Article

\title{
Surface Integrity of AISI 52100 Bearing Steel after Robot-Based Machine Hammer Peening
}

\author{
Robby Mannens *®i), Lars Uhlmann $₫$, Felix Lambers, Andreas Feuerhack and Thomas Bergs \\ Laboratory for Machine Tools and Production Engineering (WZL) of RWTH Aachen University, \\ 52074 Aachen, Germany; 1.uhlmann@wzl.rwth-aachen.de (L.U.); f.lambers@wzl.rwth-aachen.de (F.L.); \\ a.feuerhack@wzl.rwth-aachen.de (A.F.); t.bergs@wzl.rwth-aachen.de (T.B.) \\ * Correspondence: r.mannens@wzl.rwth-aachen.de; Tel.: +49-241-80-28244
}

Received: 31 May 2020; Accepted: 22 June 2020; Published: 25 June 2020

\begin{abstract}
AISI 52100 steel is often used as material for highly loaded rolling bearings in machine tools. An improved surface integrity, which can be achieved by means of mechanical surface layer finishing, can avoid premature failure. One of these finishing processes is machine hammer peening (MHP) which is a high-frequency incremental forming process and mostly used on machining centers. However, the influence of robot-guided MHP processing on the surface integrity of AISI 52100 steel is still unknown. Therefore, the objective of this work is to investigate experimentally the robot-based influences during MHP processing and the resulting surface integrity of unhardened AISI 52100 steel. The results show that the axial and lateral deviations of the robot due to process vibrations are in the lower $\mu \mathrm{m}$ range, thus enabling stable and reproducible MHP processing. By selecting suitable MHP process parameters and thus defined contact energies, even ground surfaces can be further smoothed and a hardness increase of $75 \%$ in the energy range considered can be achieved. In addition, compressive residual stress maxima of $950 \mathrm{MPa}$ below the surface and a grain size reduction to a surface layer depth of $150 \mu \mathrm{m}$ can be realized.
\end{abstract}

Keywords: machine hammer peening; bearing steel; AISI 52100; surface integrity; robot-based manufacturing; surface treatment

\section{Introduction}

\subsection{Initial Situation and Motivation}

Rolling bearings are technical elements that are used in a variety of machines to enable rotational movements. The components of rolling bearings (bearing rings and rolling elements) must withstand high cyclic loads because of over rolling [1], which consist of high contact pressures (up to $3000 \mathrm{MPa}$ ) [2], high speeds, and occasionally elevated temperatures [3] and occur with relatively small sliding movements [4]. The material requirements can be derived from the technical requirements for rolling bearings: high hardness, rolling strength and wear resistance, no structural changes and sufficient ductility [5]. Today, the components of a rolling bearing are often made of martensitic hardened and low-tempered AISI 52100 bearing steel, whereby some grades of this material class have tensile strengths $R_{m}$ greater than $2000 \mathrm{MPa}$ [6] and hardness values greater than $62 \mathrm{HRC}$ [7]. Provided that rolling bearings are correctly installed, correctly loaded and lubricated during operation and kept free of foreign bodies, their main reason for failure after a large number of load cycles is material fatigue [8]. It is assumed that bearing life is limited because of the probability of fatigue micro-cracks occurring in near-surface boundary zones, typically at a depth of 200-400 $\mu \mathrm{m}$ [6]. The local stresses in bearing contacts are determined by Hertzian theory [9], neglecting the influence of lubricants. When the bearing is properly lubricated, the phenomenon of rolling contact fatigue begins as a micro-crack 
beneath the surface, which then spreads as a macro-crack toward the surface, and when subjected to further loading leads to shell-shaped pittings [10].

One way of increasing the wear resistance and improving the fatigue resistance of AISI 52100 bearing steel is to use surface layer machining processes such as laser peening [11] and deep rolling [12]. In addition, machine hammer peening (MHP) is an alternative process for the targeted processing of technical surface layers. MHP is mainly used in the course of modern production processes, e.g., in the tool making of deep-drawing tools for the automotive industry and in the finishing of welding seams [13]. The MHP is an incremental forming process with the aim of local plastic forming of workpiece surface layers. The electrodynamic MHP is a possible process variant in which high frequency (up to $500 \mathrm{~Hz}$ ) impacts of a mostly spherical hammer head achieve a targeted smoothing [14] or structuring [15] of the surface as well as an increase in hardness and induction of compressive residual stresses [16] in the metallic workpiece surface layer. The carrier system for the electrodynamic MHP is usually a machining center due to its high stiffness and manufacturing accuracy. Although the MHP promises high machining flexibility on industrial robots, it is only rarely used today, mainly because of possible influences caused by machine vibrations [17]. While deep rolling [5] and laser peening [11] have already been the subject of research work to increase the fatigue strength of AISI 52100 bearing steel, the potentials of MHP in this field are still largely unknown. In addition, the effects of industrial robots as MHP carrier systems and their influences on the MHP machining result, which need to be taken into account, have not yet been fully researched. For these reasons, the present work deals with the investigation of the effects of robot-guided electrodynamic MHP on the surface integrity of unhardened AISI 52100 steel.

\subsection{Objective}

One objective of this paper is the quantification of the robot influences on the MHP processing result. The effects of different stiffness as well as acceleration profiles of industrial robots compared to machining centers will be considered in the context of MHP. Another objective is to analyze the cause-and-effect relationships between the energy input resulting from different MHP process parameters and the surface integrity of an unhardened AISI 52100 steel. A better understanding of the predominant interactions provides the basis for further investigations into wear and fatigue strength.

\subsection{Approach}

In a first step, the influences of an industrial robot as a carrier system in electrodynamic MHP processing are investigated. In addition to the velocity profiles, the axial and radial dynamic stiffness of the robot during MHP machining are also considered. By means of a qualitative correlation of the robot influences with the resulting surface topography and the energy input the suitability of the robot as a carrier system for electrodynamic MHP can be evaluated. In a second step, by selecting suitable MHP process parameters, different energy inputs are realized and their effects on the surface integrity (roughness, hardness, residual stresses, and grain size) are analyzed. In a third step, the experimental results are obtained and an energy-based recommendation for electrodynamic MHP processing of AISI 52100 steel is formulated.

\section{Materials and Methods}

\subsection{Analysis of Robot Dynamics}

Because of the lower stiffness of an industrial robot compared to a machining center, the robot dynamics and its influence on the hammering result were investigated before the MHP experiments. Acceleration studies were used to analyze in which areas the robot has a constant velocity, thus ensuring reproducible contact conditions for MHP. The vibration of the robot axis with the hammer tool was investigated to evaluate the machining influence on the workpiece topology. Furthermore, the elastic 
deformation of the hammer tool during MHP was investigated. This enabled a qualitative evaluation of the machine influences on the MHP processing result.

For the analysis of the robot dynamics, the electrodynamic MHP system type 2002 of accurapuls was adapted to an industrial robot ABB IRB6660-205/1.9; see Figure 1a. The structure of the electrodynamic hammer tool is shown in Figure 1b.

(a)

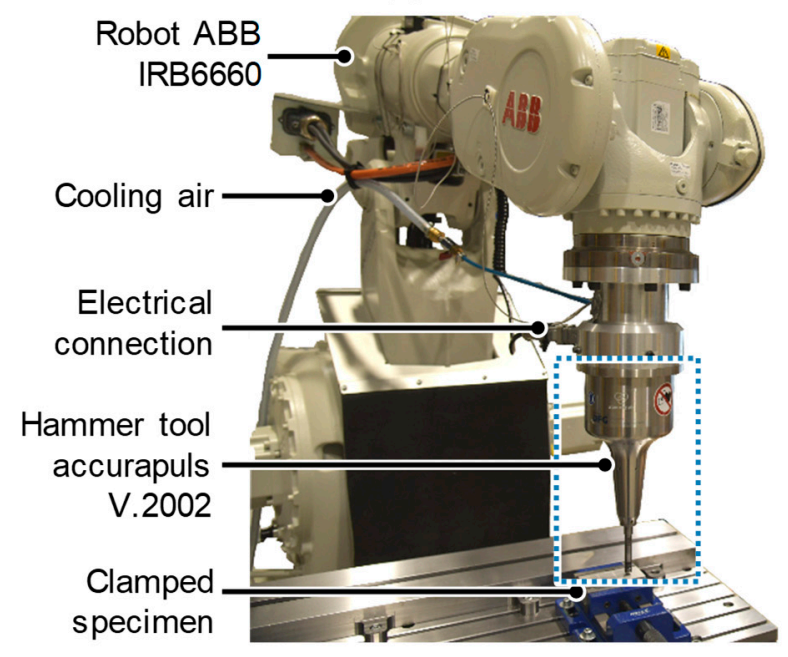

(b)

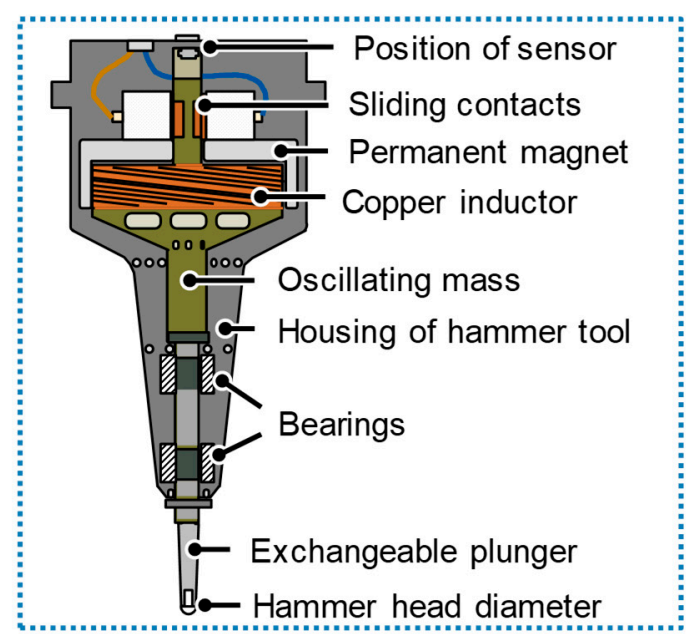

Figure 1. (a) Experimental setup for analysis of robot dynamics and machine hammer peening (MHP) tests and (b) schematic representation of the electrodynamic hammer tool.

The operating principle and process parameters of electrodynamic MHP are described in [18]. The further development of the MHP system with a fiber-optic distance sensor for inline determination of the impact energy (kinetic energy) calculated from the measured plunger stroke is already described in [19]. A relationship between impact energy and surface integrity could be established in this way. The used six-axis robot had a working range $l_{\mathrm{ra}}=1.9 \mathrm{~m}$ and a handling capacity $m_{\mathrm{r}}=205 \mathrm{~kg}$. The total mass of the hammer tool, which is attached to the robot flange via an aluminum adapter, was determined to be $m_{\mathrm{t}}=12.25 \mathrm{~kg}$.

For the analysis of the acceleration profiles of the robot used with adapted hammer tool, test series with feed rates $v_{\mathrm{r}}=120 \ldots 340 \mathrm{~mm} / \mathrm{s}$ were carried out at different frequencies $f=80,120,180 \mathrm{~Hz}$ with constant hammer head diameter $d=6 \mathrm{~mm}$, electrical power stage $P_{\mathrm{el}}=70 \%$, and stroke $h=0.8 \mathrm{~mm}$. By evaluating the distances between the resulting indentation diameters $d_{\mathrm{i}}$, the feed rate of the robot $v_{\mathrm{r}}$ could be calculated according to the following equation:

$$
v_{\mathrm{r}}=\left(x_{\mathrm{di}+1}-x_{\mathrm{di}}\right) \cdot f
$$

with $x_{\mathrm{di}}$-position of indentation along the feed axis. For analyzing the indentation diameters a Marvision MM 320 microscope was used. The tests were carried out along a path length $l_{\mathrm{x}}=70 \mathrm{~mm}$, see Figure 2a.

During MHP processing, vibrations can occur along the impact axis. For this purpose, MHP tests with hammering frequencies $f=120,180 \mathrm{~Hz}$, electrical power stage $P_{\mathrm{el}}=70 \%$, stroke $h=0.4 \mathrm{~mm}$, and indentation distance $a=0.05 \mathrm{~mm}$ were also carried out. The analysis of the specimen, plunger, and hammer tool vibration in axial (z-) impact direction was done using an Aramis system from GOM, see Figure $2 b$. Based on triangulation, 3D displacements were optically recorded in real time for point-based measurements.

To investigate the elastic deformation of the oscillating mass in the hammer tool during MHP, finite element (FE) analyses were performed in SolidWorks 2019. Since elastic deformations of the vibrating mass can influence the detected plunger stroke and thus the contact energy, it was necessary 
to consider them. AISI 4140 was selected as material for the oscillating components. The reaction forces were varied between $F_{\mathrm{r}}=0.5 \ldots 2.5 \mathrm{kN}$. This range was chosen because the hammering forces of the inserted hammering system were determined by means of a Kistler 9257B force-measuring platform in previous works. The simulation procedure was based on the work of Habersohn [18], see Figure 2c.

Using a micro-structured plunger with a hammer head diameter $d=10 \mathrm{~mm}$ and a hammering frequency $f=120 \mathrm{~Hz}$, the machining deviations due to vibration of the carrier system (robot) parallel and perpendicular to the hammering direction were investigated. The micro-structured area on the hammer head had a diameter $d_{\mathrm{m}}=100 \mu \mathrm{m}$ and a depth $t_{\mathrm{m}}=2 \mu \mathrm{m}$, see Figure $2 \mathrm{~d}$.

(a)

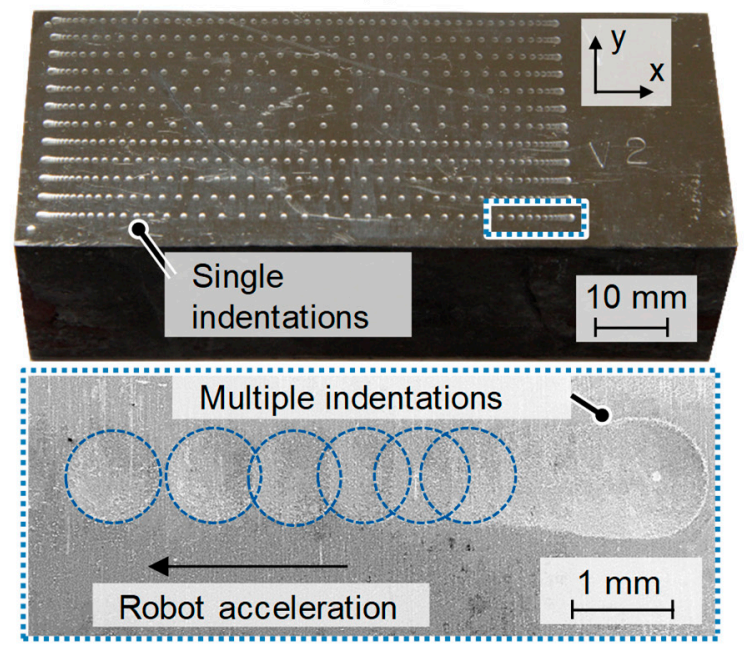

(c)

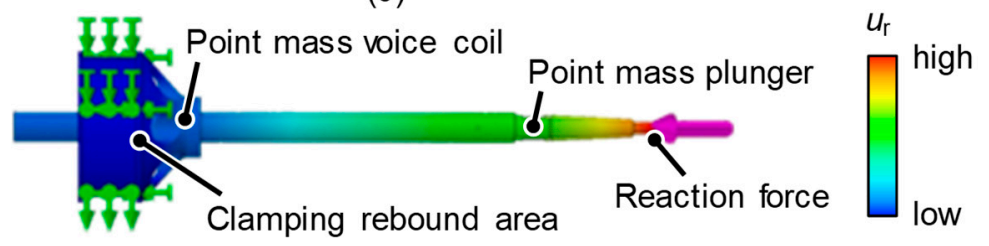

(b)

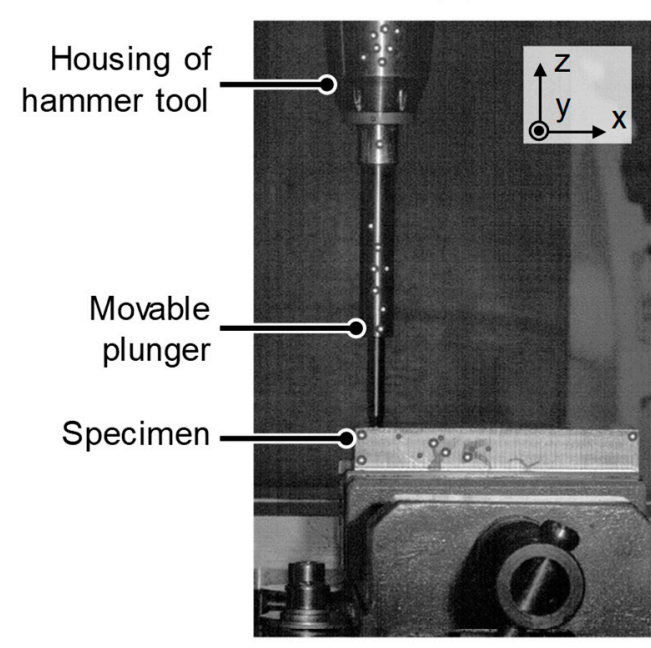

(d)

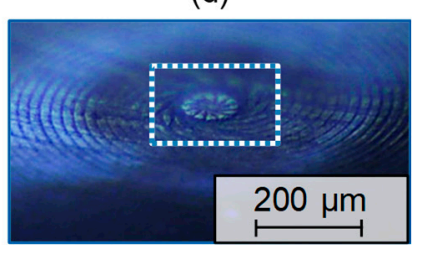

Figure 2. (a) Determination of robot acceleration analyzing single indentations, (b) section of test setup with point markings using the GOM-Aramis system for analysis of axial (z) MHP vibration, (c) FE-analysis of elastic deformation of oscillating mass in SolidWorks, and (d) micro-structured area on hammer head.

\subsection{MHP Test Bench Environment and Characterisation Methods}

The MHP tests were also carried out with an industrial robot ABB IRB6660 and an electrodynamic hammer system type 2002 from accurapuls. After the preliminary tests for characterization of the dynamic robot behavior and the indentation accuracy, MHP tests were carried out. Therefore, AISI 52100 specimens with the dimension $100 \times 40 \times 30 \mathrm{~mm}(\mathrm{~L} \times \mathrm{W} \times \mathrm{H})$ were used. When delivered, the specimens were in a forged and annealed condition according to DIN 7527. For reproducible initial conditions of the specimens, their surfaces were subsequently ground plane-parallel. The specimens were not subjected to heat treatment, since the primary objective was to investigate fundamental cause-and-effect relationships between the contact energy in robot-guided MHP and the resulting surface integrity. A further analysis with heat-treated AISI 52100 steel with regard to the transferability of the cause-effect relationships identified in this work is planned for the future. The chemical composition determined by means of spark spectroscopy meets the requirements of DIN EN ISO 683-17. The values averaged over three measurements with the corresponding standard deviations $\sigma$ are given in Table 1. 
Table 1. Extract of the spectral analysis results of the AISI 52100 specimens.

\begin{tabular}{cccccccccc}
\hline & $\mathbf{C}$ & $\mathbf{S i}$ & $\mathbf{M n}$ & $\mathbf{P}$ & $\mathbf{S}$ & $\mathbf{C r}$ & $\mathbf{M o}$ & Al & $\mathbf{C u}$ \\
\hline $\mathrm{wt} \%$ & 0.955 & 0.251 & 0.391 & 0.012 & 0.005 & 1.510 & 0.015 & 0.028 & 0.141 \\
$\sigma(\mathrm{wt} \%)$ & 0.019 & 0.001 & 0.003 & $<0.001$ & $<0.001$ & 0.008 & $<0.001$ & 0.003 & $<0.001$ \\
\hline
\end{tabular}

The initial microstructure of the AISI 52100 specimen was analyzed by means of light (Figure 3a) and scanning electron microscopy (Figure 3b). The homogeneous microstructure contains perlite with secondary cementite on the grain boundaries. The lamellar cementite of the perlite structure is spherically formed by the previous annealing of the steel and secondary spherical carbide inclusions are formed. For microscopic analysis, the specimens were first nickel-plated and then conductively hot-embedded. Grinding was carried out with 320 ... 2500 grit abrasive paper (SiC). Subsequently, the specimens were mechanically polished for $10 \mathrm{~min}$ each step starting with $6 \mu \mathrm{m}$, followed by 3 $\mu \mathrm{m}$ and $1 \mu \mathrm{m}$ ethanol-based diamond suspension. The selected contact pressure was $F_{\text {prep }}=10 \mathrm{~N}$. Colloidal silica suspension (OP-S) was the final preparation step to achieve a deformation-free surface for high orientation contrast in EBSD analysis. For light microscopic analysis, the ground and polished specimen cross sections were etched with a $1 \% \mathrm{HNO}_{3}$ solution. A Zeiss Axio Imager $\mathrm{M} 2 \mathrm{~m}$ microscope was used for light microscopic analyses and a Zeiss Sigma 500 VP field emission scanning electron microscope for SEM analyses. Furthermore, for SEM analysis a combined EDX/EBSD system (NordLys nano camera and Aztec software) from Oxford Instruments was used. The backscatter electrons (BSE) and secondary electrons (SE) SEM investigations were performed using an accelerating voltage of $10 \mathrm{kV}$ with working distances $W D=5 \ldots 10 \mathrm{~mm}$. EBSD analysis were performed at an accelerating voltage of $20 \mathrm{kV}$ and $W D=12 \ldots 14 \mathrm{~mm}$.

(a)

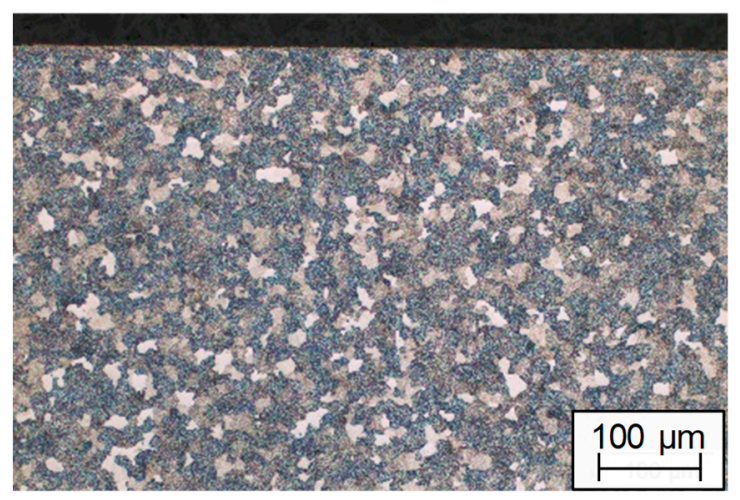

(b)

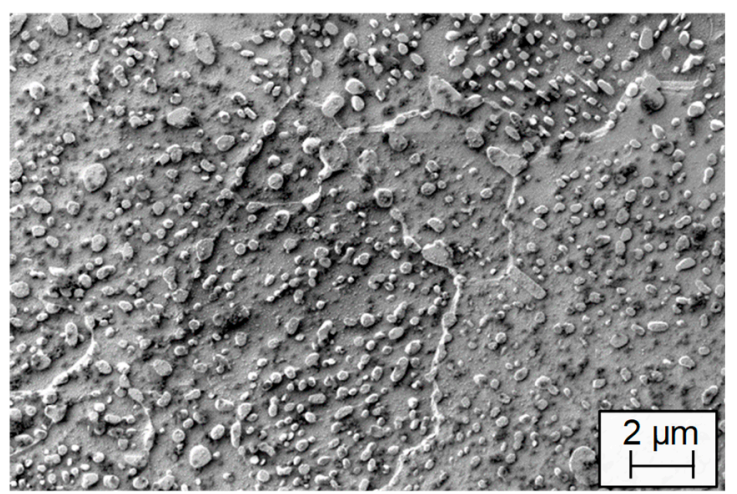

Figure 3. (a) Light microscopic and (b) SEM analysis of initial microstructure of AISI 52100 specimen.

The MHP parameter setups and corresponding contact energies $E_{\mathrm{c}}=7 \ldots 40 \mathrm{~mJ}$ were defined as follows, see Table 2. Three valid repetitions were carried out for each experiment.

Table 2. MHP test setups for surface layer machining of AISI 52100 specimen.

\begin{tabular}{cccccccccc}
\hline & \multicolumn{7}{c}{ Test Series } \\
\hline No. & $\mathbf{1}$ & $\mathbf{2}$ & $\mathbf{3}$ & $\mathbf{4}$ & $\mathbf{5}$ & $\mathbf{6}$ & $\mathbf{7}$ & $\mathbf{8}$ & $\mathbf{9}$ \\
\hline$a(\mathrm{~mm})$ & & & & & 0.05 & & & & \\
$f(\mathrm{~Hz})$ & & & & & 120 & & & 12 & \\
$d(\mathrm{~mm})$ & & 6 & & & 10 & & & 0.5 \\
$h(\mathrm{~mm})$ & 0.1 & 0.3 & 0.5 & 0.1 & 0.3 & 0.5 & 0.1 & 0.3 & 0.5 \\
$E_{\mathrm{c}}(\mathrm{mJ})$ & 7 & 20 & 40 & 7 & 20 & 40 & 7 & 20 & 40 \\
$w\left(\mathrm{~mJ} / \mathrm{mm}^{2}\right)$ & 2800 & 8000 & 16,000 & 2800 & 8000 & 16,000 & 2800 & 8000 & 16,000 \\
\hline
\end{tabular}


A symmetrical surface structure was hammered on all fields with indentation distance $a=$ stepover distance $b=0.05 \mathrm{~mm}$. All tests listed were carried out with one overrun $(n=1)$. Using the given indentation and path distances and the number of overruns, an energy density per $\mathrm{mm}^{2}(w)$ was calculated. The hammering frequency $f$, the hammer head diameter $d$, and the plunger stroke $h$ were chosen according to previous works [19]. A meandering machining strategy was therefore selected. Furthermore, the lubricant Castrol Viscogen KL3 was chosen and all tests were carried out with an impact angle $\beta_{\mathrm{i}}=0^{\circ}$, which corresponds to an orthogonal alignment of the hammer tool to the specimen surface. The electrical power stage was set to $P_{\mathrm{el}}=70 \%$ for all tests, which corresponds to an electrical power $P=470 \mathrm{~W}$.

The surface roughness of the specimens was determined by means of a measuring system Hommel Etamic T8000 RC according to ISO 25178 on $1.6 \times 1.6 \mathrm{~mm}$ measuring fields. The surface macro hardness according to Vickers was determined by four-fold repeated measurement and subsequent averaging using a Zwick Roell Indentec ZHU250 hardness tester according to DIN EN ISO 6507-1. By means of a Fischerscope HM2000 hardness tester the microhardness according to Vickers was determined. The measuring points along the surface layer depth had a distance of $75 \mu \mathrm{m}$. In each surface layer depth eight measurements were made for statistical verification. The depth profiles of the residual stresses were measured with the PRISM hole drilling system from Stresstech according to the principle of electronic speckle pattern interferometry (ESPI) [20].

\section{Results and Discussion}

In the following, the results of the surface layer analysis are presented. Besides the results of surface roughness and hardness, microhardness and residual stress curves into the surface layer depth after MHP are also shown. In addition, first results on the effect of MHP on the grain size distribution using EBSD analyses are presented.

\subsection{Robot Acceleration}

Figure 4 shows the results of the robot acceleration analyses. The indentation diameters were in the range $d_{\mathrm{i}}=0.930 \ldots 1.065 \mathrm{~mm}$. It can be seen that the acceleration profiles of the robot can be divided into three areas: positive, zero, negative. As the feed rate increases, the set robot speed is reached later and the range of constant robot speed is reduced.

(a)

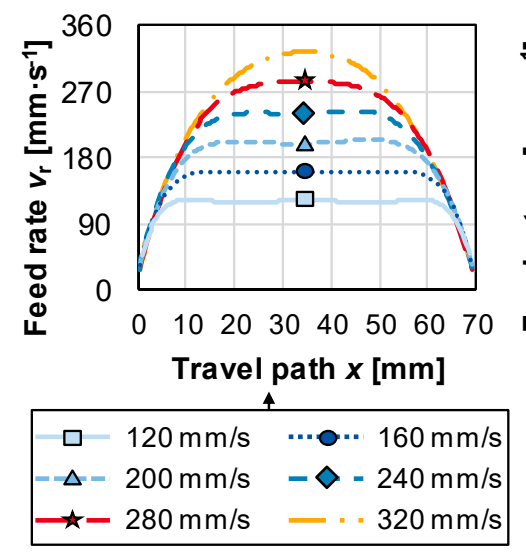

(b)

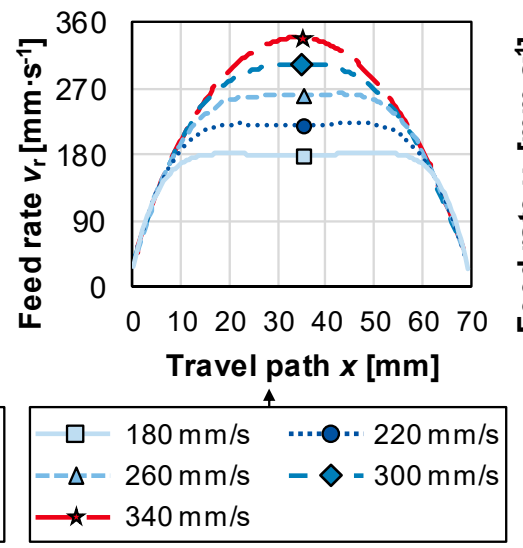

(c)

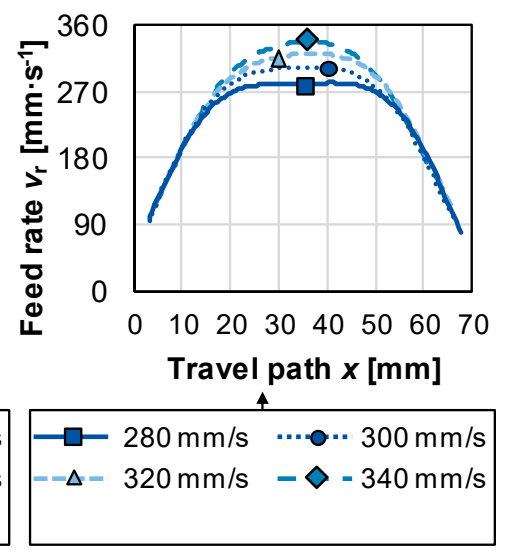

Figure 4. Evaluation of robot acceleration for different feed rates $v_{\mathrm{r}}=120 \ldots 340 \mathrm{~mm} \cdot \mathrm{s}^{-1}$ for hammering frequencies (a) $f=80 \mathrm{~Hz}$, (b) $f=120 \mathrm{~Hz}$, and (c) $f=180 \mathrm{~Hz}$.

With MHP, an overlap of at least $50 \%$ in the feed direction as well as in the direction of the path distance is often aimed for. Assuming that an indentation distance $a=1 \mathrm{~mm}$ is desired at hammering frequencies $f=120 \ldots 180 \mathrm{~Hz}$, the feed rate is calculated as $v_{\mathrm{r}}=60 \ldots 100 \mathrm{~mm} \cdot \mathrm{s}^{-1}$. Accordingly, it is 
expected that those lower feed rates in the case of surface machining will lead to a further increase in the range of the constant robot velocity. The topic of different velocity profiles in robot-based MHP processing and the resulting uneven energy input due to different numbers of individual impacts has already been addressed by Krall [21]. By a targeted coupling of the MHP system via a serial interface with the robot, the MHP parameters electrical power stage $P_{\mathrm{el}}$ and hammering frequency $f$ can be specifically adapted depending on the robot feed rate $v_{r}$. However, the approach presented was not taken up in this paper, as the investigation of fundamental cause-and-effect relationships between the MHP and the surface integrity of AISI52100 bearing steel should be addressed. The acceleration characteristics of the robot were therefore taken into account by selecting analysis areas of constant and reproducible boundary conditions. It could be determined that independently of the selected hammering frequency $f$, the positive and negative acceleration $a_{\mathrm{r}}$ can be described with the following equations for the feed rate $v_{\mathrm{r}}$ independently of the selected hammering frequency $f$ :

$$
\begin{array}{ll}
a_{\mathrm{r}}>0: & v_{\mathrm{r}}(\mathrm{x})=7.14 \cdot \mathrm{x}+100.9 \\
a_{\mathrm{r}}<0: & v_{\mathrm{r}}(\mathrm{x})=-6.22 \cdot \mathrm{x}+549.5
\end{array}
$$

\subsection{Robot Vibration and Indentation Profiles during MHP}

Figure $5 \mathrm{a}$ shows the axial movement of the hammer tool at $f=120 \mathrm{~Hz}$ along a hammering path. It is obvious that regarding the MHP with workpiece contact the axial movement of the hammer tool increases compared to the MHP without workpiece contact. In the parameter range considered, the maximum movement of the hammer tool was $\Delta z \approx 40 \mu \mathrm{m}$ (area between dotted orange lines). This corresponds to approximately $10 \%$ of the set stroke. Because of the high stiffness of the robot, the influence of vibration on the impact energy applied is therefore negligible. Nonetheless, the comparison with a previous work on the robot-based MHP shows that the influence of different industrial robots on the processing result with the electrodynamic MHP must always be individually evaluated [17]. In this work, with activated MHP system, but without workpiece contact, the maximum movement was $\Delta z<20 \mu \mathrm{m}$.

Furthermore, it was investigated in which range the eigenfrequency of the robot lies in order to avoid a processing influence. The eigenfrequency is described as the free and undamped oscillation of the robot as carrier system for the MHP tool. The analysis of the eigenfrequency of the robot should exclude that it is in a similar range as the used hammering frequencies $f$ of the MHP system. The hammering frequency is the frequency which is set at the beginning of the MHP process and which describes the number of impacts per second of the plunger on the workpiece surface. If the frequency ranges are superimposed, the vibration amplitudes could be amplified, thus influencing the plunger stroke and resulting in different contact energies of individual hammer impacts. Therefore, the dynamic behavior of the robot was described by transferring a defined time segment of the oscillation signal with activated MHP (with contact) into the frequency domain using fast Fourier transformation (FFT); see Figure $5 \mathrm{~b}$. The eigenfrequency of the robot is $f_{\mathrm{R}}=42.5 \mathrm{~Hz}$, the used hammering frequency $f=120 \mathrm{~Hz}$ is also visible. Since MHP processing of the samples with hammering frequencies $f=120$, $180 \mathrm{~Hz}$ should be executed, no influence of the eigenfrequency on surface integrity was expected.

The slight oscillation of the carrier system (robot axis with hammer tool) during MHP lead to undesired surface effects, see Figure 5 c. By repeated wavelet transformations (spline; different filter levels) the output profile was decomposed to make the waviness visible. In (2) the individual hammer impacts and the machining paths resulting from MHP machining are visible. In (1), however, the waviness caused by the robot vibrations is undesired and prevents a defined surface structuring. Nevertheless, the size range of the unintentionally induced waviness due to the robot oscillation is very small. The surface morphologies determined after MHP tests support this statement. Furthermore, the analysis of the elastic deformation of the vibrating mass in the hammer tool by the impacts on the workpiece surface confirmed the results of Habersohn [18]. By varying the reaction forces $F_{\mathrm{r}}=$ 
$0.5 \ldots 2.5 \mathrm{kN}$, maximum elastic compressions of the vibrating mass $u_{\mathrm{r} \text {,max }}=5 \ldots 15 \mu \mathrm{m}$ were determined. The influence of the elastic compression on the set plunger stroke and thus the resulting energy input into the workpiece surface was therefore also neglected.

(a)

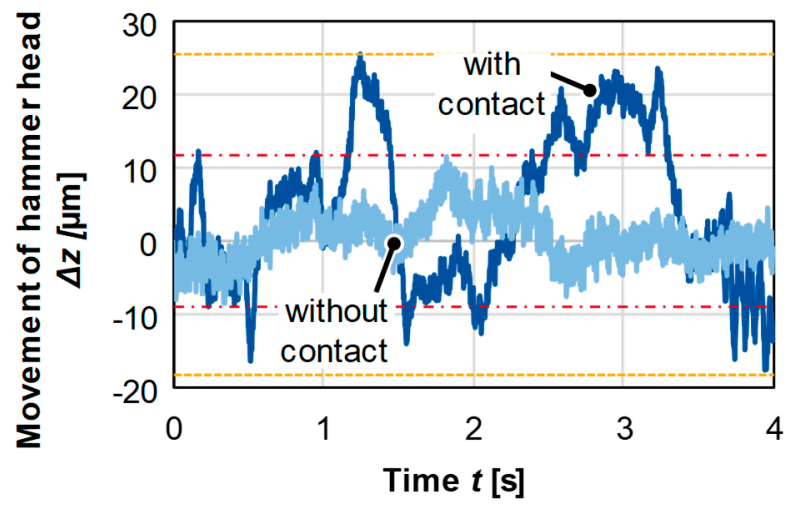

(b)

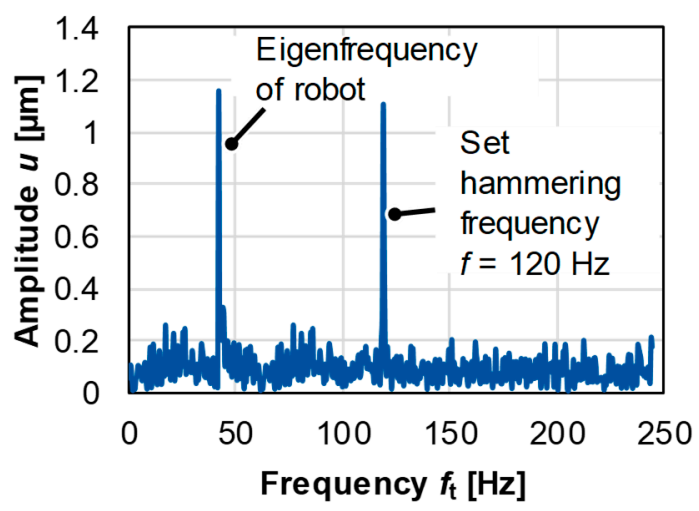

(c)

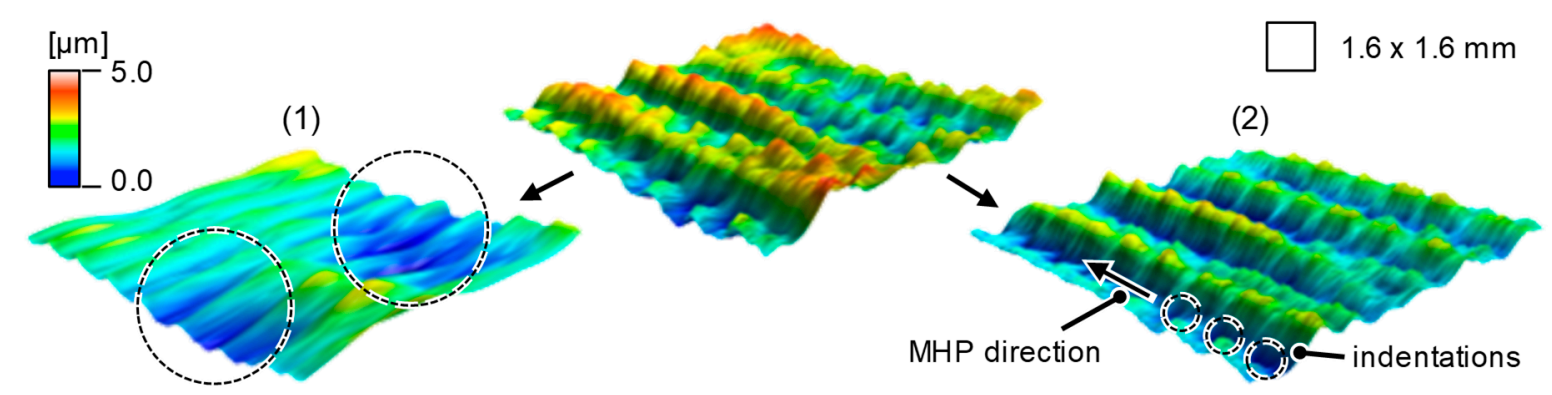

Figure 5. Analysis of (a) axial hammer head movement, (b) eigenfrequency of the robot, and (c) defined waviness due to adjusted hammer paths (2) and unwanted waviness due to robot vibrations (1) on the workpiece surface for a set hammering frequency $f=120 \mathrm{~Hz}$, a hammer head diameter $d=10 \mathrm{~mm}$ and a plunger stroke $h=0.5 \mathrm{~mm}$.

Using a hammering frequency $f=120 \mathrm{~Hz}$, it was found that in the area of a constant robot velocity the indentations in feed direction $(x)$ were equidistant and macroscopic in line, see Figure $6 a$. The deviation in positive $(+y)$ and negative $(-y)$ direction along the feed axis was at maximum $\Delta y=$ $80 \mu \mathrm{m}$ (Diff.). A high positional repeatability of the robot along the feed axis in the area of constant robot velocity is therefore given. However, adjacent paths (y-direction) show a partly significant displacement, which is due to the turning points during path changes of meandered machining. An exact positioning of the individual indentations of adjacent paths is not possible due to the process characteristics. In some cases, larger deviations can occur $\Delta x_{\max } \approx 300 \mu \mathrm{m}$ (area between red lines), whereby the deviations are still within the range of a single indentation diameter $\left(d_{\mathrm{i}} \approx 1 \mathrm{~mm}\right)$.

In summary, it can be stated that vibrations on the robot model considered here in axial and radial direction during MHP treatment have a slight influence on the processing result. Thus, a basic suitability for the use of the robot model in MHP could be proven. Furthermore, it could be shown that only very small elastic deformations of the component oscillating in the hammer tool occur during electrodynamic MHP and a significant influence on the measured plunger stroke and thus on the contact energy and energy density can be excluded. However, these system influences were neglected for the following analysis of cause-and-effect relationships between MHP process parameters and surface integrity of an AISI 52100 steel. 
(a)

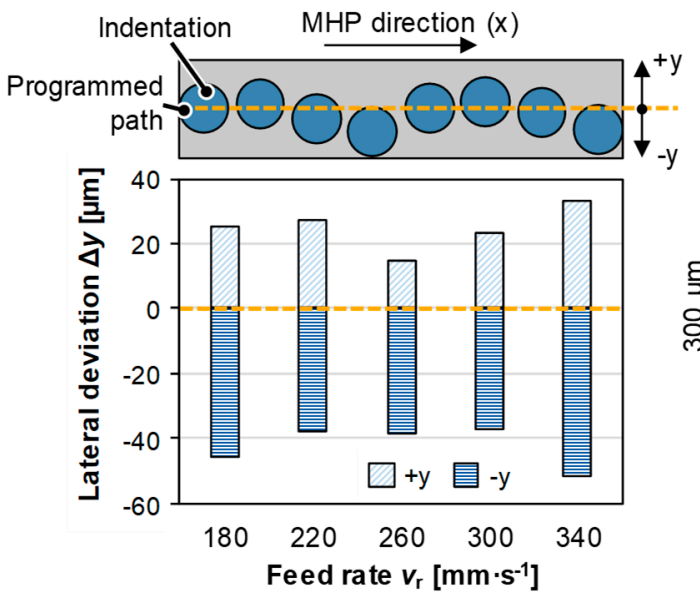

(b)

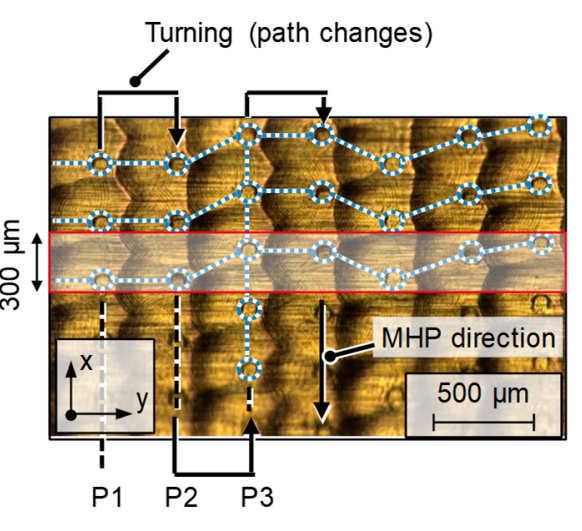

Figure 6. (a) Deviation of indentations along feed axis (MHP direction) and (b) process-related deviation of indentations of adjacent MHP paths for a hammering frequency $f=120 \mathrm{~Hz}$, a hammer head diameter $d=10 \mathrm{~mm}$, and a plunger stroke $h=0.5 \mathrm{~mm}$.

\subsection{Surface Roughness}

The results of roughness measurements are shown in Figure 7a. Besides the maximum height $S z$ the arithmetical mean height $S a$ was considered, since it is robust against small superficial impurities on the specimen surface. The influence of outliers is thus minimized. With increasing stroke $h=0.1$ ... $0.5 \mathrm{~mm}$ both roughness values increase significantly. This finding confirms the results of Krall on Al-2024-T351 [21], Bleicher et al. on unhardened DIN 1.2379 tool steel [22] and Lechner et al. on DIN 1.1191 steel [23]. The tendency in the size of the hammer head diameter is not evident. There is a preference to set a lower roughness value with larger hammer head diameters. This coincides with the investigations of Wied [24]. Nonetheless, the best results were achieved with a hammer head diameter $d=10 \mathrm{~mm}$. However, a separate consideration of the influence of the hammer head diameter is insufficient. A supplementary consideration of the interaction of the hammer head diameter with the indentation and path distance would be useful in future work.

An influence, for e.g., imperfections or a flattening of the plunger surface could be excluded by profile and SEM analyses of the plunger surface before the tests were carried out, see Figure $7 \mathrm{~b}$. Only the plunger with $d=6 \mathrm{~mm}$ showed minimal signs of use. The maximum radial deviations from the idealized reference profile were $\Delta r=1.5 \mu \mathrm{m}$. No wear of the ball surface was detected on the plungers used after the MHP tests. By using a stroke $h=0.1 \mathrm{~mm}$, the lowest roughness values $S a=0.153 \mu \mathrm{m}$ and $S z=2.22 \mu \mathrm{m}$ could be achieved. This corresponds to a reduced roughness of $40 \%(S a)$ and $60 \%$ $(S z)$ compared to the ground initial surface.

However, it must also be mentioned that the roughness was considered in a range of constant MHP conditions without the influence of boundary areas. Lechner first described the effect of material throw-up during MHP machining [23]. This effect occurs in the transition zone between machined and unmachined surface areas. The material is advanced in the machining direction by the tangential contact between the plunger and the workpiece surface. This causes a material accumulation. In addition to lowering the machining area, this also leads to the initial level being exceeded. Furthermore, the last machining path is finally lowered in relation to the previously machined surface. In the case of MHP machining over the entire surface and the aim of achieving uniform, low surface roughness, this circumstance must be taken into account. A possible approach to avoid such material throw-ups is described by Krall [21]. 
(a)

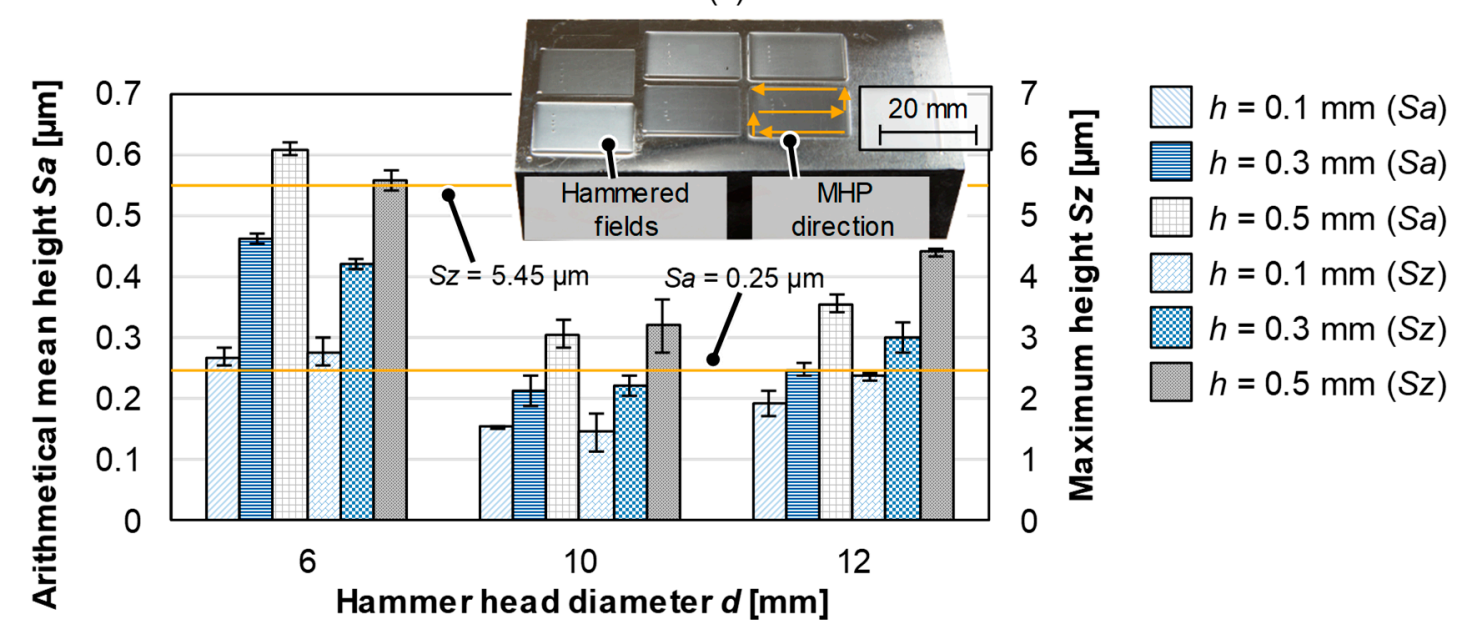

(b)
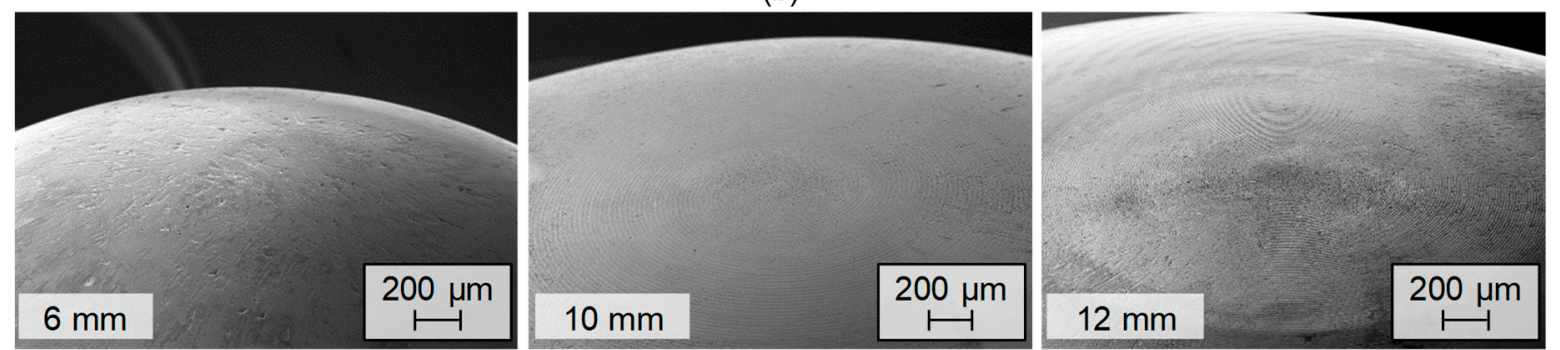

Figure 7. (a) Results of roughness measurements for different strokes h; horizontal orange lines: ground surface; (b) SEM-analysis of plunger surfaces before MHP experiments.

\subsection{Surface Layer Hardness}

The results of surface hardness HV5 are shown in Figure 8. In all MHP setups there has been an increase in surface hardness. It can be seen that a small hammer head diameter $d$ in combination with increasing plunger stroke $h$ leads to higher hardness values HV5. These observations were also made by Adjassoho et al. [25], Bleicher et al. [22], and Scheil et al. [26] on materials of different initial hardness and heat treatment conditions. A higher stroke $h$ results in a higher plunger acceleration and thus higher contact energy $E_{\mathrm{c}}$. A smaller hammer head diameter $d$ results in a higher Hertzian pressure. The combination of these two effects leads to a stronger plastic deformation of the surface layer and thus to an increased work hardening. The predominant mechanism for increasing hardness is dislocation hardening. In addition, the formation of sub-grain structures by increasing dislocation density could also have an influence on the increase in hardness [27]. However, too high contact energies can also lead to dislocation annihilation and thus to a reduction in strength, as shown in [21,22]. For the steel materials under consideration in the mentioned work above, the maximum increase in hardness was $20 \%$. With a hardness increase of 55\% (from 200 to 310 HV5), the AISI 52100 steel under consideration here shows pronounced hardening behavior. Individual spot tests with a hammer head diameter $d=6 \mathrm{~mm}$, a stroke $h=1.1 \mathrm{~mm}$, and number of overruns $n=1 ; 2$, i.e., increased contact energy per impact $E_{\mathrm{C}}=70 \mathrm{~mJ}$ and energy density $w=28,000$ (ME-medium energy); $56,000 \mathrm{~mJ} / \mathrm{mm}^{2}$ (HE-high energy) even showed an increase in hardness of 75\% (347 HV5). It is noticeable that when using larger hammer head diameters $d=10 ; 12 \mathrm{~mm}$, a significantly lower increase in hardness was achieved with increasing stroke. 


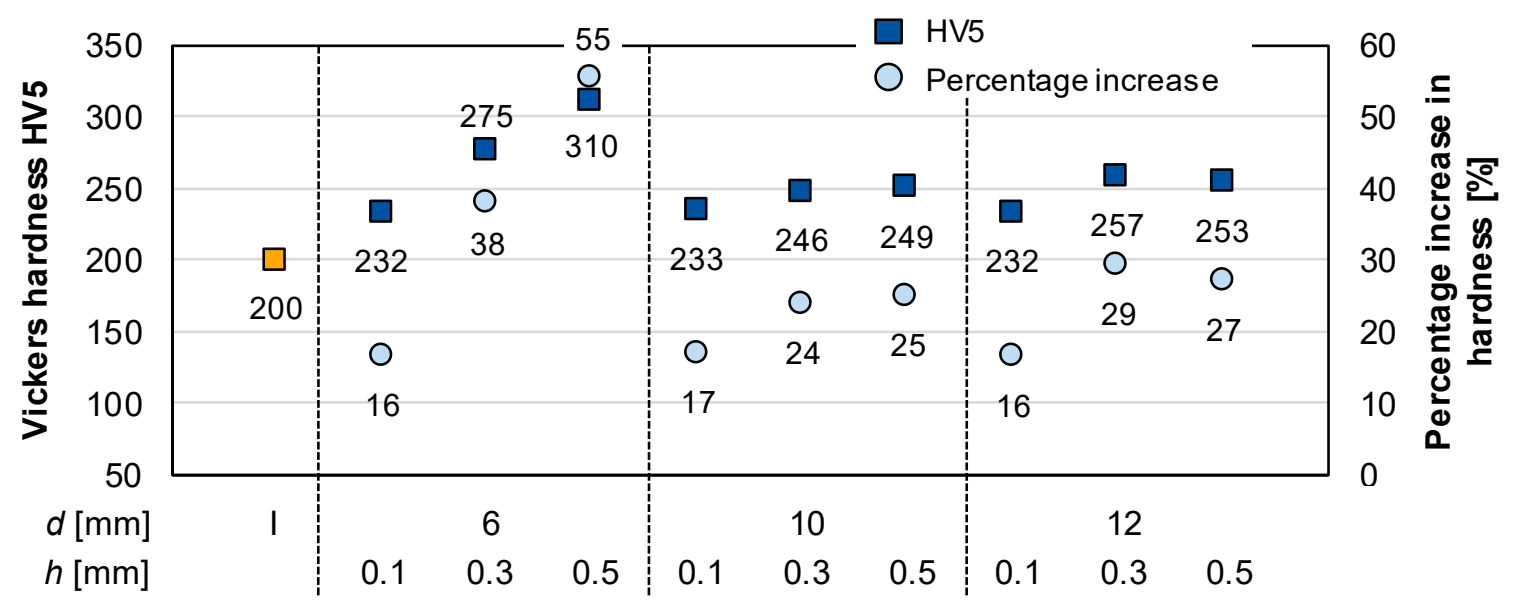

Figure 8. Analysis of surface hardness HV5. Legend: I-initial hardness (ground state); $d$-hammer head diameter; $h$-stroke.

The results of the microhardness measurement are presented in Figure 9. The microhardness in the initial state was determined as an average value of $242 \pm 7$ HV0.1. MHP machining has led to an increase in hardness in the surface layer close to the surface between $16 \ldots 55 \%$. One reason for the high increase in hardness is the work hardening of the material brought about by MHP, which in turn is due to a sharp increase in dislocation density. Depending on the energy applied, in addition to the formation of sub-grain structures consisting of dislocation arrangements in the form of cell walls and nuclei, grain refinement can also occur, which can explain an increase in hardness according to the Hall-Petch relationship [27]. By introducing a low energy density ( $\mathrm{MOH} 4: d_{10}, h_{0.1}, n_{1}$ ) only an increase in hardness up to a surface layer depth $z=500 \mu \mathrm{m}$ could be achieved. By increasing the energy density (MOH 6: $d_{10}, h_{0.5}, n_{1}$ ), the effect of the hardness increase was again significantly enhanced. This extends to a surface layer depth $z=1200 \mu \mathrm{m}$. The spot tests with medium (ME: $d_{6}, h_{1.1}, n_{1}$ ) and a high energy density $w$ (HE: $d_{6}, h_{1.1}, n_{2}$ ) led to a further increase in hardness. By using MHP with high energy density an increase in hardness up to $z=1500 \mu \mathrm{m}$ could be achieved. The increase in hardness thus extends further into the surface layer depth than the compressive residual stresses introduced. Klumpp et al. also reported an increase in hardness in the surface layer of a hardened AISI 52100 bearing steel hammered by means of piezoelectric MHP at room temperature and cryogenically, where hardening was achieved to a surface layer depth $z>650 \mu \mathrm{m}$ [28].

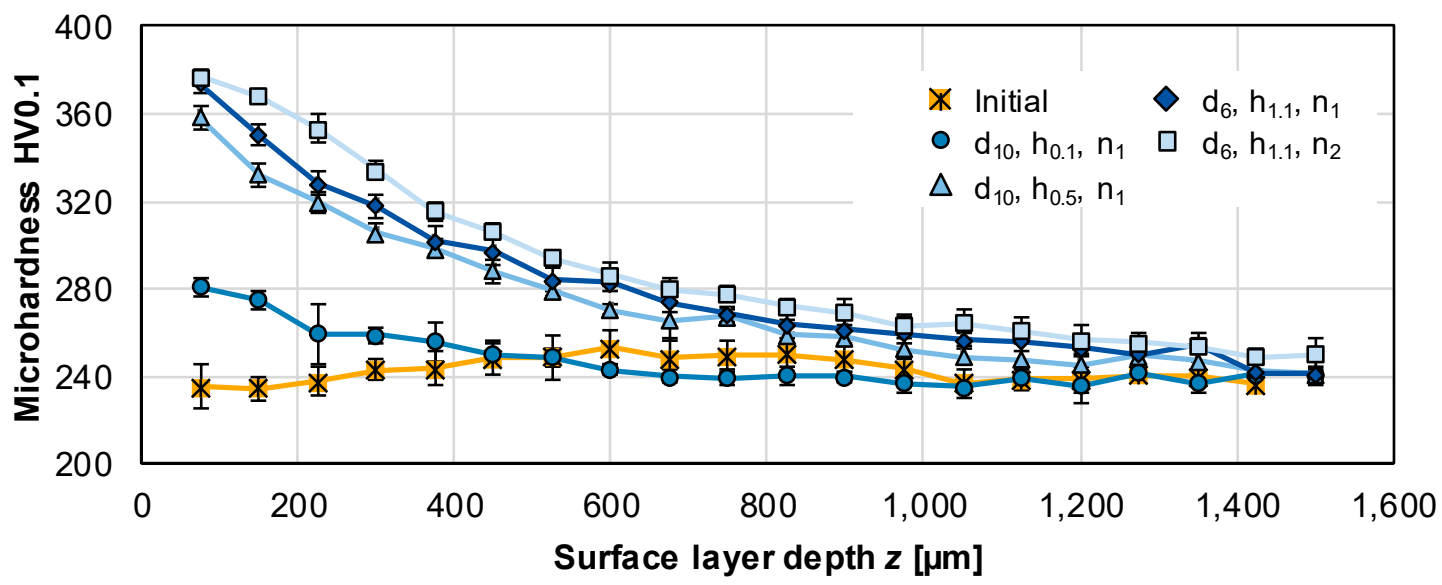

Figure 9. Micro hardness distribution of untreated (initial) and MHP-treated specimen with different hammer head diameters $d$, stroke $h$, and number of overruns $n$. 


\subsection{Residual Stresses}

The results of the residual stress measurements are shown in Figure 10a. The measured residual stresses orthogonal to the MHP feed direction $\sigma_{\mathrm{x}}$ are greater than parallel to the feed direction $\sigma_{\mathrm{y}}$, which was also first reported for electrodynamic MHP from Medvedeva et al. [29]. This anisotropy of residual stresses is due to MHP processing in adjacent paths. The primary material deformation is orthogonal to the MHP feed direction, resulting in higher plastic deformations and thus higher compressive residual stresses [23]. Therefore, in the following only the orthogonal residual stresses $\sigma_{\mathrm{x}}$ were considered. It can be seen that high compressive residual stress maxima $\sigma_{x, \max }$ were introduced by all MHP setups below the surface. The mechanism of plastic surface elongation is therefore superimposed by the Hertzian pressure. Depending on the MHP setups selected, these were between $\sigma_{x, \max }=-950 \ldots$ $-580 \mathrm{MPa}$ and in surface layer depths $z=40 \ldots 100 \mu \mathrm{m}$. The zero crossing for almost all MHP setups was approximately at a surface layer depth $z=300 \ldots 350 \mu \mathrm{m}$ (grey area). The highest compressive residual stresses were achieved with a hammer head diameter $d=6 \mathrm{~mm}$ and a stroke $h=0.5 \mathrm{~mm}$. As with surface hardness, this can also be justified by the combination of high contact energy and high Hertzian pressure.

(a)

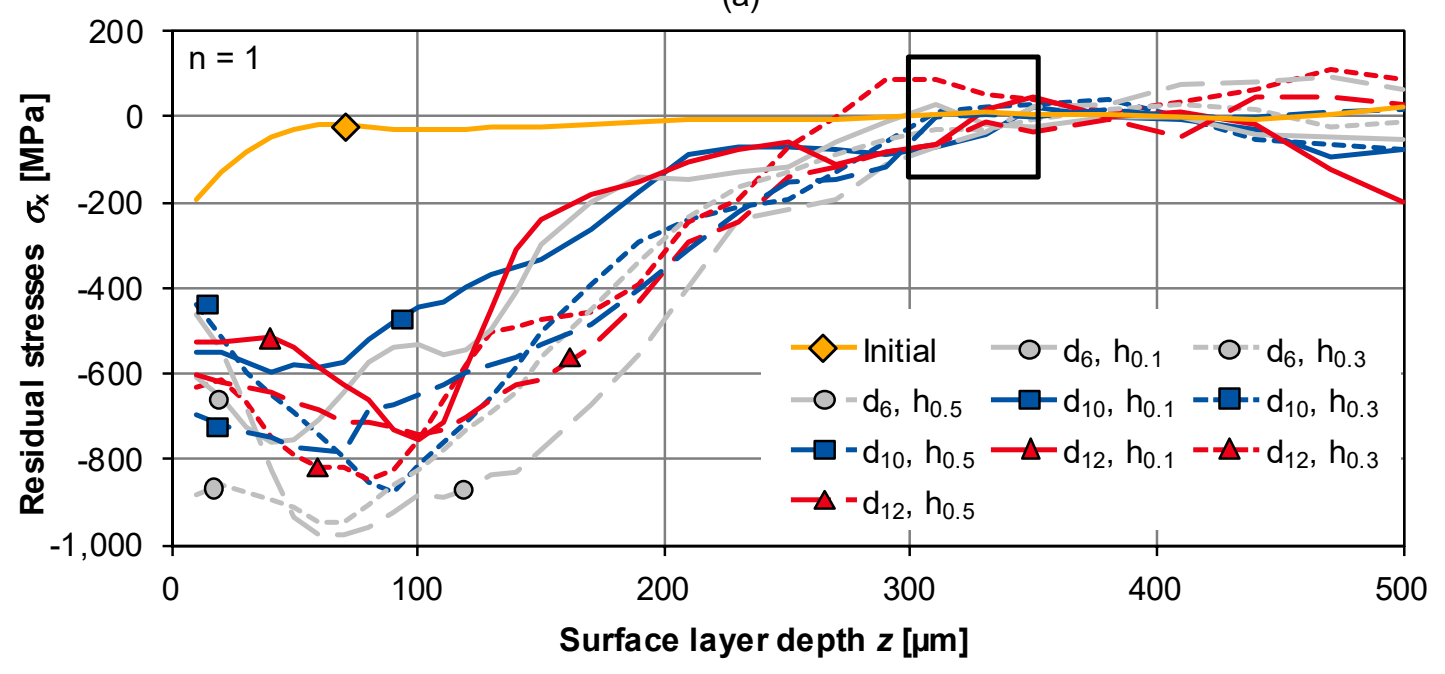

(b)
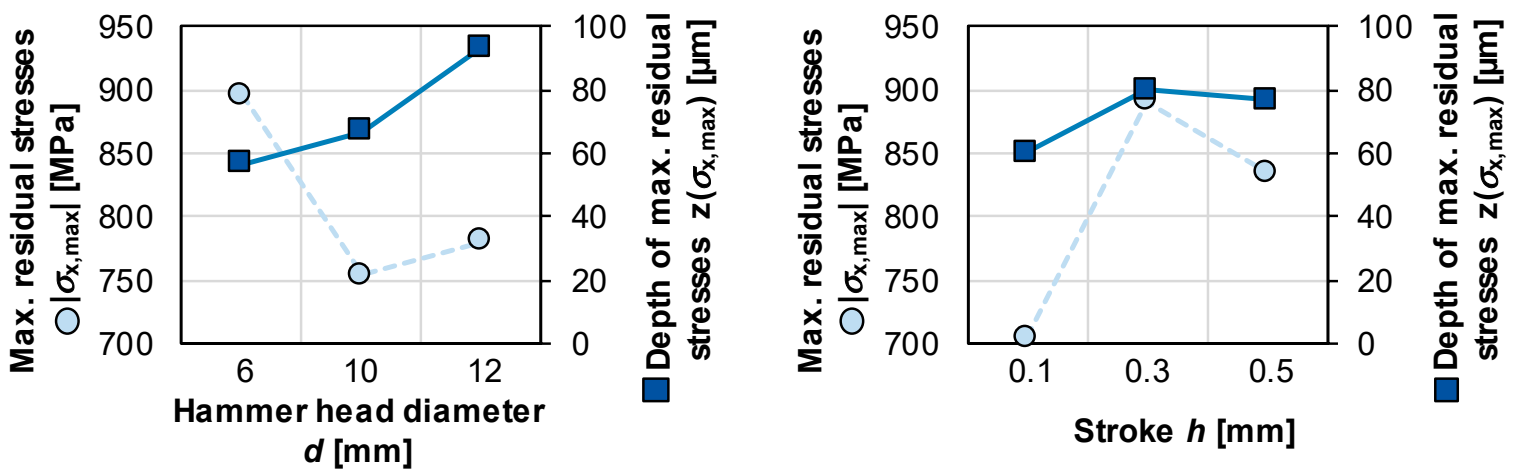

Figure 10. (a) Illustration of the residual stress curves with zero crossing for almost all MHP setups and (b) main effect plots of averaged maximum compressive residual stresses $\sigma_{x, \max }$ and corresponding depth $z$. 
The main effect diagrams shown in Figure $10 \mathrm{~b}$ for the parameters hammer head diameter $d$ and plunger stroke $h$ on the compressive residual stress maximum and the surface layer depth of the compressive residual stress maximum show no clear effects. Only a shift of the maximum compressive residual stresses toward greater surface layer depths with larger hammer head diameters was observed. A clear correlation between a larger hammer head diameter and the associated lower compressive residual stress maxima, as described in [30], could not be observed.

For the same hammer head diameter, an increase in the plunger stroke tends to lead to higher compressive residual stresses. However, this effect decreases with increasing hammer head diameter. From this, it can be concluded that for a given indentation and path distance the interactions between hammer head diameter and plunger stroke must be considered. It must be mentioned that because of the measuring method of the hole drilling method, especially the residual stresses near the surface can be subject to uncertainties. A supplementary consideration by means of XRD analyses is therefore planned in the future to confirm the residual stresses. Nevertheless, by means of hole drilling method the tendencies regarding changes in residual stress curves due to changes in MHP process parameters could be shown very well.

\subsection{Grain Size}

The results of grain size analysis after MHP are shown in Figure 11. For EBSD analysis the specimen hammered with high energy density $w=56,000 \mathrm{~mJ} / \mathrm{mm}^{2}$ was chosen. Figure 11a shows the IPF map with areas of different grain sizes from the hammered surface into the surface layer. The view describes the normal direction to the sample surface. A fine-grained area was observed with a surface layer depth $z=90 \mu \mathrm{m}$. The corresponding distribution of grain sizes is shown in Figure 11b. Most of the grains lie in the grain size range $d_{\mathrm{G}}<1 \mu \mathrm{m}$. Below the fine-grained area a transition zone about $60 \mu \mathrm{m}$ wide has been formed. Only after about $150 \mu \mathrm{m}$ below the surface the initial state of the AISI 52100 sample was observed. Figure 11c shows the corresponding distribution of grain sizes of the initial state. In comparison with the fine-grained area, the significant reduction in grain size can be confirmed. Here most of the grains were in a size range $d_{\mathrm{G}}=1 \ldots 40 \mu \mathrm{m}$. The results confirm the grain refining influence of MHP on the surface layer as already described by Chen et al. [31]. As these are first results of grain size analysis according to the MHP of AISI 52100 steel, further investigations must be carried out in future with regard to the forming texture and dislocation development in order to describe the mechanisms in the surface layer qualitatively. 
(a)

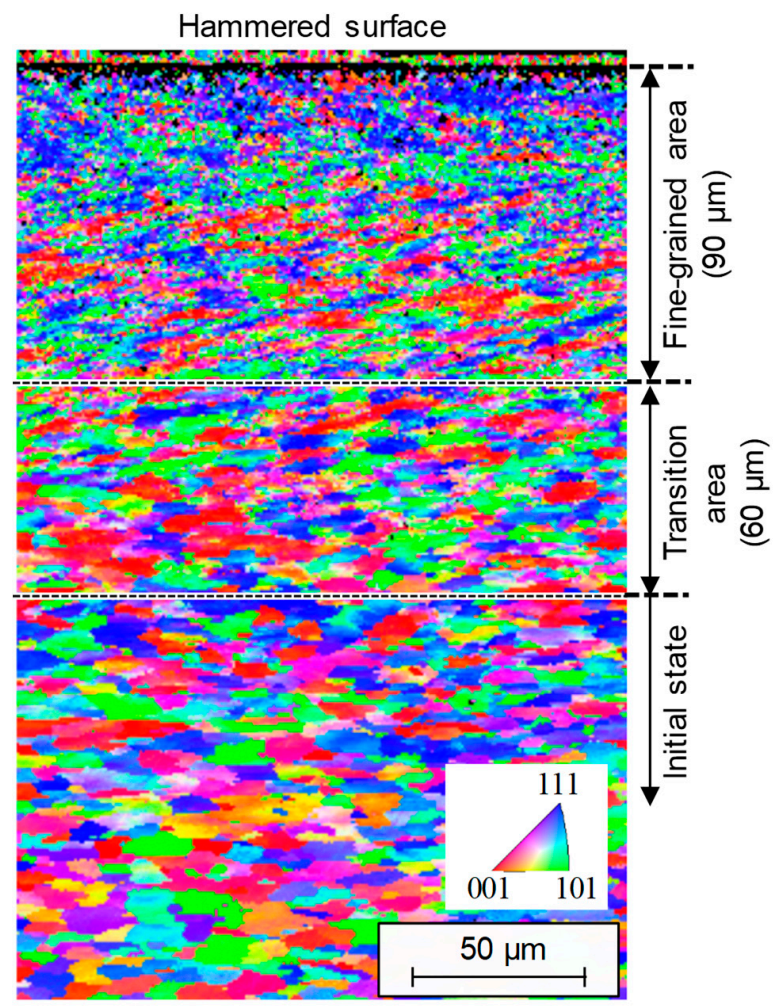

(b)

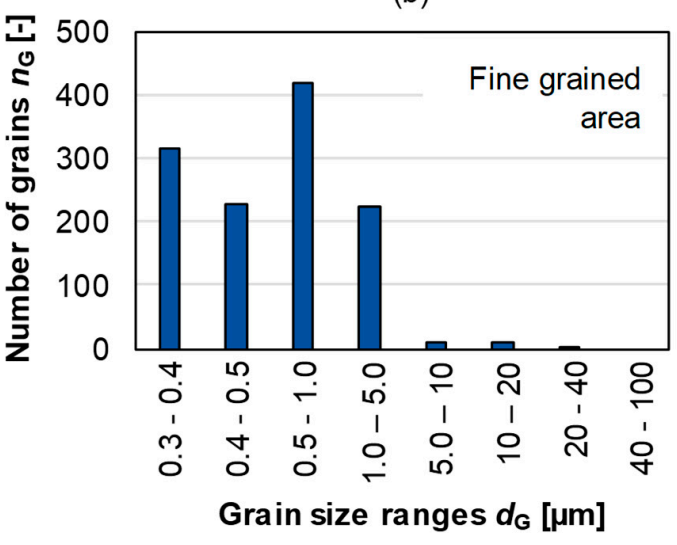

(c)

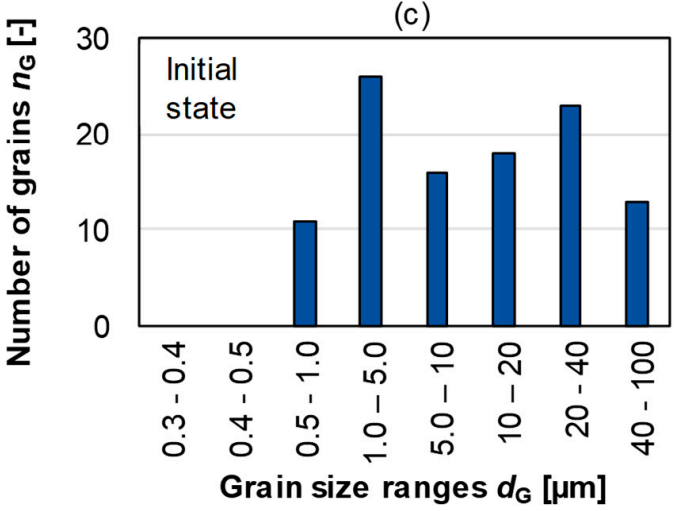

Figure 11. (a) IPF map for grain size analysis for MHP-treated surface layer with $d=6 \mathrm{~mm}, h=1.1 \mathrm{~mm}$, and $n=2$; histogram of the grain size distribution of $(\mathbf{b})$ the fine-grained area and (c) the initial state.

\section{Conclusions}

Within the scope of this research, the influence of the dynamic behavior of an industrial robot on the machining result was analyzed for high-frequency electrodynamic MHP. Furthermore, the cause-and-effect relationships between selected process parameters in electrodynamic MHP and the resulting surface integrity of an unhardened AISI 52100 bearing steel were investigated for the first time. The results of the analysis of an industrial robot ABB IRB 6660/205-1.9 as carrier system for an electrodynamic MHP system show the basic applicability and can be summarized as follows:

- Independent of the selected feed rate of the industrial robot, the range of constant feed rate and thus reproducible MHP conditions can be described mathematically.

- Because of the high robot stiffness (eigenfrequency $f_{\mathrm{r}}=42.5 \mathrm{~Hz}$ ), the lateral deviation during MHP processing along a hammering path and along the impact axis are very small. Therefore, this robot enables reproducible MHP processing with regard to a defined energy density.

The analysis of the surface layer properties according to the electrodynamic MHP of unhardened AISI 52100 has also shown the potential of this innovative manufacturing process. The results can be summarized as follows:

- Depending on the contact energy and energy density, the electrodynamic MHP can not only smoothen but also roughen the surface. A reduction of the roughness $S z$ by $60 \%$ compared to a milled surface can be achieved. A large hammer head diameter and a small stroke tend to be advantageous.

- The surface hardness can be increased by $75 \%$ in the considered MHP parameter range and an effective depth of hardening of $z=1500 \mu \mathrm{m}$ can be achieved. A high plunger stroke and a small hammer head diameter are particularly advantageous. 
- High compressive residual stress maxima $\sigma_{\mathrm{x}, \max }=-950 \ldots-580 \mathrm{MPa}$ were introduced below the surface. A small hammer head diameter and high stroke tend to lead to higher compressive residual stress maxima.

- A significant grain size reduction down to the submicron range could be achieved down to a surface layer depth $z=150 \mu \mathrm{m}$.

Based on the results generated in this work, which basically qualify industrial robots as carrier systems of the electrodynamic MHP and show the positive influence of the electrodynamic MHP on the surface integrity of AISI 52100, further analyses regarding grain size and orientation as well as dislocation densities can be performed in the future. In addition, after selection of suitable MHP process parameters, an analysis of the fatigue and wear resistance can be carried out in rotating bending tests and pin-on-cylinder tests in order to quantify the positive influence of MHP-treated surface layers on the component life. The conflict of interest between a surface that is as smooth as possible to avoid crack initiation points and the highest possible compressive residual stress maxima and effective depths of the hardened surface layer as well as reduced grain sizes will be a particular challenge.

Author Contributions: Conceptualization, R.M. and L.U.; methodology, R.M.; formal analysis, L.U. and A.F.; investigation, R.M. and F.L.; resources, A.F. and T.B.; data curation, R.M. and F.L.; writing-original draft preparation, R.M.; writing-review and editing, R.M. and L.U.; visualization, R.M.; supervision, A.F. and T.B.; project administration, A.F. and T.B.; funding acquisition, T.B. All authors have read and agreed to the published version of the manuscript.

Funding: This research was funded by the German Research Foundation (DFG) within the projects "Grain refinement in the surface layer of metallic components by means of machine hammer peening-FinePeening (grant number: KL500/170-1, project number: 326729428)" and "Optimization of the application behavior of spur gears by machine-hammered tooth surfaces-OptiGear (grant number: KL500/192-1, project number: 390969378)".

Conflicts of Interest: The authors declare no conflict of interest.

\section{References}

1. Šmelova, V.; Schwedt, A.; Wang, L.; Holweger, W.; Mayer, J. Electron microscopy investigations of microstructural alterations due to classical Rolling Contact Fatigue (RCF) in martensitic AISI 52100 bearing steel. Int. J. Fatigue 2017, 98, 142-154. [CrossRef]

2. Kang, J.-H.; Rivera-Díaz-del-Castillo, P.E.J. Carbide dissolution in bearing steels. Comput. Mater. Sci. 2013, 67, 364-372. [CrossRef]

3. Fu, H.; Song, W.; Galindo-Nava, E.I.; Rivera-Díaz-del-Castillo, P.E.J. Strain-induced martensite decay in bearing steels under rolling contact fatigue: Modelling and atomic-scale characterization. Acta Mater. 2017, 139, 163-173. [CrossRef]

4. Hannes, D.; Alfredsson, B. Modelling of surface initiated rolling contact fatigue damage. Procedia Eng. 2013, 66, 766-774. [CrossRef]

5. Neubauer, T. Betriebs- und Lebensdauerverhalten Hartgedrehter und Festgewalzter Zylinderrollenlager. Ph.D. Thesis, Gottfried Wilhelm Leibniz University, Hannover, Germany, 2016.

6. Barrow, A.T.W.; Rivera-Díaz-del-Castillo, P.E.J. Nanoprecipitation in bearing steels. Acta Mater. 2011, 59, 7155-7167. [CrossRef]

7. Kreuser, J. Konstruktion und Aufbau eines Wälzlagerprüfstands zur Untersuchung von Hybrid- und Keramikwälzlagern. Ph.D. Thesis, RWTH Aachen University, Aachen, Germany, 2007.

8. Warhadpande, A.; Sadeghi, F.; Evans, R.D. Microstructural alterations in bearing steels under rolling contact fatigue part 1-Historical overview. Tribol. Trans. 2013, 56, 349-358. [CrossRef]

9. Rycerz, P.; Olver, A.; Kadiric, A. Propagation of surface initiated rolling contact fatigue cracks in bearing steel. Int. J. Fatigue 2017, 97, 29-38. [CrossRef]

10. Kerscher, E.; Lang, K.H.; Vöhringer, O.; Löhe, D. Increasing the fatigue limit of a bearing steel by dynamic strain aging. Int. J. Fatigue 2008, 30, 1838-1842. [CrossRef] 
11. Yakimets, I.; Richard, C.; Béranger, G.; Peyre, P. Laser peening processing effect on mechanical and tribological properties of rolling steel 100Cr6. Wear 2004, 256, 311-320. [CrossRef]

12. Röttger, K. Walzen Hartgedrehter Oberflächen. Ph.D. Thesis, RWTH Aachen University, Aachen, Germany, 2002.

13. Schulze, V.; Bleicher, F.; Groche, P.; Guo, Y.B.; Pyun, Y.S. Surface modification by machine hammer peening and burnishing. CIRP Ann.-Manuf. Technol. 2016, 65, 809-832. [CrossRef]

14. Trauth, D.; Klocke, F.; Welling, D.; Terhorst, M.; Mattfeld, P.; Klink, A. Investigation of the surface integrity and fatigue strength of Inconel718 after wire EDM and machine hammer peening. Int. J. Mater. Form. 2016, 9, 635-651. [CrossRef]

15. Trauth, D. Tribology of Machine Hammer Peened Tool Surfaces for Deep Drawing. Ph.D. Thesis, RWTH Aachen University, Aachen, Germany, 2016.

16. Bleicher, F.; Lechner, C.; Habersohn, C.; Kozeschnik, E.; Adjassoho, B.; Kaminski, H. Mechanism of surface modification using machine hammer peening technology. CIRP Ann.-Manuf. Technol. 2012, 61, 375-378. [CrossRef]

17. Krall, S.; Lechner, C.; Nirtl, M.; Bleicher, F. Robot based machine hammer peening using an electromagnetic driven hammering device. In Annals of DAAAM, Proceedings of 26th DAAAM International Symposium on Intelligent Manufacturing and Automation, Zadar, Croatia, 21-24 October 2015; Katalinic, B., Ed.; Curran Associates, Inc.: New York, NY, USA, 2016.

18. Habersohn, C. Analytische und Simulative Betrachtung eines Oberflächenhämmerprozesses. Ph.D. Thesis, Vienna University of Technology, Vienna, Austria, 2015.

19. Mannens, R.; Uhlmann, L.; Feuerhack, A.; Bergs, T. Energy-Dependent Surface Integrity of Stainless Steel AISI 304 after Robot-Based Machine Hammer Peening. In Proceedings of the 13th International Conference on the Technology of Plasticity (ICTP), Columbus, OH, USA, 25-30 July 2021. (accepted).

20. Schajer, G.S.; Rickert, T.J. Incremental Computation Technique for Residual Stress Calculations Using the Integral Method. Exp. Mech. 2011, 51, 1217-1222. [CrossRef]

21. Krall, S. Beeinflussung der Randschicht Durch Diskrete Mikroumformung. Ph.D. Thesis, Vienna University of Technology, Vienna, Austria, 2019.

22. Bleicher, F.; Lechner, C.; Habersohn, C.; Obermair, M.; Heindl, F.; Rodriguez-Ripoll, M. Improving the tribological characteristics of tool and mould surfaces by machine hammer peening. CIRP Ann.-Manuf. Technol. 2013, 62, 239-242. [CrossRef]

23. Lechner, C. Oberflächenmodifikation unter Einsatz der Technologie des Schlagverdichtens (Machine Hammer Peenings). Ph.D. Thesis, Vienna University of Technology, Vienna, Austria, 2014.

24. Wied, J. Oberflächenbehandlung von Umformwerkzeugen Durch Festklopfen. Ph.D. Thesis, Technical University of Darmstadt, Darmstadt, Germany, 2011.

25. Adjassoho, B.; Kozeschnik, E.; Lechner, C.; Bleicher, F.; Goessinger, S.; Bauer, C. Induction of residual stresses and increase of surface hardness by machine hammer peening. In Annals of DAAAM, Proceedings of 23rd DAAAM International Symposium on Intelligent Manufacturing and Automation, Zadar, Croatia, 24-27 October 2012; Katalinic, B., Ed.; DAAAM International: Vienna, Austria, 2012.

26. Scheil, J.; Müller, C.; Steitz, M.; Groche, P. Influence of Process Parameters on Surface Hardening in Hammer Peening and Deep Rolling. Key Eng. Mater. 2013, 554-557, 1819-1827. [CrossRef]

27. Lienert, F. Bauteiloptimierung Mittels Piezopeening-Auswirkungen auf den Randschichtzustand und die Schwingfestigkeit von 42CrMo4 V450. Ph.D. Thesis, Karlsruhe Institute of Technology KIT, Karlsruhe, Germany, 2017.

28. Klumpp, A.; Tamam, M.A.; Vollert, F.; Dietrich, S.; Schulze, V. Influence of conventional and cryogenic piezo peening on bending fatigue strength of hardened bearing steel AISI 52100. In Proceedings of the 13th International Conference on Shot Peening, Montréal, QC, Canada, 18-21 September 2017; pp. 435-440.

29. Medvedeva, A.; Berglund, J.; Wied, J.; Gunnarsson, S. Surface characteristics of different tool steels and cast iron after machine hammer peening. In Proceedings of the 4th International Swedish Production Symposium, Lund, Sweden, 3-5 May 2011; pp. 212-218. 
30. Hessert, R.; Bamberg, J.; Satzger, W.; Taxer, T. Ultrasonic Impact Treatment for Surface Hardening of the Aero-Engine Material IN718. In Proceedings of the 10th International Conference on Shot Peening, Tokyo, Japan, 15-18 September 2008.

31. Chen, T.; John, H.; Xu, J.; Lu, Q.; Hawk, J.; Liu, X. Influence of surface modification on pitting corrosion behaviour of nickel-base alloy 718. Part 1: Effect of machine hammer peening. Corros. Sci. 2013, 77, 230-245. [CrossRef]

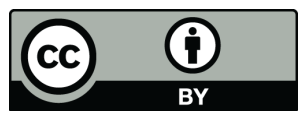

(C) 2020 by the authors. Licensee MDPI, Basel, Switzerland. This article is an open access article distributed under the terms and conditions of the Creative Commons Attribution (CC BY) license (http://creativecommons.org/licenses/by/4.0/). 